John Carroll University

Carroll Collected

Sociology

$10-2013$

\title{
Fetal Sex Determination and Gendered Prenatal Consumption
}

\author{
Medora W. Barnes \\ John Carroll University, mbarnes@jcu.edu
}

Follow this and additional works at: http://collected.jcu.edu/soc-facpub

Part of the Family, Life Course, and Society Commons, and the Gender and Sexuality Commons

\section{Recommended Citation}

Barnes, Medora W., "Fetal Sex Determination and Gendered Prenatal Consumption" (2013). Sociology. 20.

http:// collected.jcu.edu/soc-facpub/20

This Article is brought to you for free and open access by Carroll Collected. It has been accepted for inclusion in Sociology by an authorized administrator of Carroll Collected. For more information, please contact connell@jcu.edu. 


\section{Journal of Consumer Culture}

http://joc.sagepub.com/

Fetal sex determination and gendered prenatal consumption Medora W Barnes

Journal of Consumer Culture published online 7 October 2013

DOI: $10.1177 / 1469540513505606$

The online version of this article can be found at:

http://joc.sagepub.com/content/early/2013/10/07/1469540513505606

Additional services and information for Journal of Consumer Culture can be found at:

Email Alerts: http://joc.sagepub.com/cgi/alerts

Subscriptions: http://joc.sagepub.com/subscriptions

Reprints: http://www.sagepub.com/journalsReprints.nav

Permissions: http://www.sagepub.com/journalsPermissions.nav

>> OnlineFirst Version of Record - Oct 7, 2013

What is This? 


\title{
Fetal sex determination and gendered prenatal consumption
}

\section{Medora W Barnes}

Department of Sociology, John Carroll University, USA

\begin{abstract}
Although expectant mothers have long purchased items in preparation for their baby's birth, the timing and type of purchases being made have changed in response to pregnant women routinely learning the sex of their fetus through ultrasound. This article examines changes in these consumption patterns through data drawn from personal narratives with 25 women divided between two cohorts - those who gave birth in the 2000 s and those who gave birth in thel970s. The routine use of ultrasound has encouraged changes in beliefs about the relationship between a fetus and its mother in younger women, which in turn inspires earlier purchases of baby items than was normative 30 years before. Not enough attention is being paid to the fact that newborn babies are more likely today than three decades ago to spend their first few months wearing gendered clothing and being surrounded by gender-specific furniture and objects, which their mothers are purchasing during pregnancy.
\end{abstract}

\section{Keywords}

Pregnancy, mother, ultrasound, gender, baby

\section{Introduction}

The types of items women purchase is due to the meanings they give to their situation, which in turn helps produce new meanings. In recent years, more attention has focused on women, and especially on mothers, as consumers. The consumption patterns of mothers are different than the individualist consumer model sometimes assumed in economics, for a significant amount of their consumption is on behalf of others - their children, their spouses, their households (Cook, 2004, 2008; DeVault, 1991). Over the last 20 years, how shopping for one's family helps to "produce family" has begun to receive more attention. Although dependent

\section{Corresponding author:}

Medora W Barnes, Department of Sociology and Criminology, John Carroll University, I John Carroll Blvd., University Heights, OH 44I I8, USA.

Email: mbarnes@jcu.edu 
children require other types of carework as well, one important category of caring work includes buying and provisioning good and services for the household, in addition to planning and preparing the purchases (DeVault, 1991; Hochschild, 2003; Miller, 1998; Pugh, 2009).

When dealing with very young children who cannot consent or chose consumer products, the mothers' consumption choices are a form of socialization for her children. The toys, clothes, and other products that parents buy are part of the social construction of their children's worlds (Lorber, 1994; Martens, 2004). Although it is often assumed that socialization begins at birth, when mothers purchase items before their children are born, socialization and consumption can be seen as beginning before birth.

Although mothers have been purchasing items in preparation for their baby's birth since the advent of the market economy, over the last few decades the nature of those purchases has shifted, along with the timing and types of purchases being made. This article specifically examines changes in these consumption patterns, as part of a larger study about how finding out the sex of one's fetus through ultrasound has changed the experience of pregnancy over the last 30 years. It does this by comparing the personal narratives of women who gave birth in the 2000s with those who gave birth approximately 30 years earlier. It argues that the routine use of ultrasound, especially for fetal sex determination, plays an important role in consumption patterns because it encourages certain beliefs and types of consuming on behalf of the unborn child.

\section{Emergence of ultrasound technology}

Although ultrasound technology (also known as a sonogram or ultrasonograph) was developed in the early 1930s and 1940s, it was not until the 1980s that its use became common in the United States. In recent decades, its use has become ubiquitous even in the lives of pregnant women undergoing "normal" pregnancies, as the medicalization of reproduction has increased and the use of obstetric technologies, such as ultrasound, has been routinized (Katz Rothman, 1989, 1994; Oakley, 1980, 1984). Ultrasound photographs have also been used in a variety of ways, from anti-abortion materials that use ultrasound images as visual evidence that the fetus is already "a baby" and hence that abortion is murder, to other less ideologically loaded usages, such as advertisements intended to encourage the purchase of baby products (Haraway, 1997; Petchesky, 1987; Taylor, 2000, 2008). Ultrasounds have changed how society views fetuses literally and culturally, with ultrasound being identified as "a pedagogy for learning to see who exists in the world" (Haraway, 1997: 177).

Since the experience of ultrasound became common, both medical and social scientists have found that ultrasound may help pregnancy seem "real" earlier and encourage expectant women to bond more closely with their unborn babies (Gregg, 1995; Mitchell, 2001; Mitchell and Georges, 1997; Petchesky, 1987; Sandelowski, 1994). Mitchell (2001) also found that having an ultrasound encouraged expectant 
mothers to view their fetus as a "baby" before its birth. The minimal cross-cultural research that is available found significant differences between expectant mothers in Canada and Greece (Mitchell and Georges, 1997). Canadian mothers were more likely to see their unborn babies as already developing identities before the child was born than were Greek mothers due to ways the fetus' behavior was constructed during the ultrasound process.

One aspect of ultrasounds that has not received adequate attention is how discovering the sex of one's fetus may affect expectant mothers' beliefs or behaviors. Until the last few decades, expectant mothers found out the sex of their baby at their birth. Today the majority of mothers are now choosing to find out the sex of their baby ahead of time, frequently through their routine ultrasounds (Marleau and Saucier, 2002). Women in the United States who have health insurance usually have two ultrasounds scheduled during a "normal" pregnancy, with those deemed to be "high risk" often having more. The first one occurs between 8 and 10 weeks and is used to check for abnormalities and determine a due date. The second occurs at approximately 20 weeks and is used to check for growth and abnormalities, and can be used to visually determine the biological sex of the fetus in most instances. Although ultrasound is the most common way that perspective parents learn the sex of their fetus, women who choose to have certain types of prenatal genetic testing (often amniocentesis or chorionic villus) can also learn whether their child has an XX or XY chromosome.

Scholars have documented the many ways in which gender is used to organize interactions, social institutions, and system of inequalities (Lorber, 1994; West and Zimmerman, 1987); however, little is known about how discovering the sex of one's fetus affects the interactions and behaviors of pregnant women. Although not her main focus, Mitchell (2001) reported that pregnant women sometimes felt closer to their unborn baby after learning its sex. Other researchers have found that when pregnant women discover their unborn baby is the opposite sex to their preferred one, this can have a negative influence on how close they feel to it (Gregg, 1995).

\section{Expectant mothers as consumers}

Newborn babies do require certain things to allow them to sleep, feed, and eliminate safely. Nonetheless, the baby industry in the US has grown greatly in the last few decades and seems to be gaining influence in encouraging expectant mothers to consume on behalf of their unborn babies far beyond what is necessary (Bailey and Ulman, 2005; Taylor 2000, 2008). The growing number of items expectant parents in the US are buying is influenced by many factors, including the power of the baby industry and the development of new safety standards (Bailey and Ulman, 2005; Taylor, 2008). In addition, as the majority of babies in the US are now born into dual-earner or single parent families where all adults are working (Casper and Bianchi, 2001), products marketed as time- or labor-saving devices may be especially appealing to new parents. 
Consuming on behalf of one's children has come to be viewed as an important part of motherhood (Layne, 2000; Miller, 1998; Taylor, 2008; Taylor et al., 2004); therefore, when pregnant women buy things for their unborn babies, it can be seen as a step in assuming their role of mother. In addition, the actual material objects purchased can be used to help construct social identities (mother and child) and the relationship between them (Layne, 2000; Taylor, 2008). Miller (1998) argues that shopping can be seen as a ritual of sacrifice that is part of a relationship of love and care, where consumers (who are primarily mothers) think about the individual preferences of those for whom they are buying.

Traditionally, consumer choices were theorized to be strongly related to several class-based constraints, which included economic wealth, types of cultural knowledge, and access to social networks (Bourdieu, 1984). In more recent years, economic restructuring and globalization have made it more difficult to read displays of goods as signs of social status due to the range of goods and styles available on the global market (Featherstone, 1991). While individuals now have more freedom of choice, they also have the responsibility to create their own identity through their consumption patterns (Giddens, 1991). As consumers play a more active role in the creation of their individual identities through consuming, this can lead to anxiety that they are making the correct decisions (Warde, 1994).

When mothers are consuming on behalf of their child, there may be additional anxiety, as they worry about whether they are making the "right" decision (Martens, 2004; Warde, 1994). If the consumption choices the mother makes on behalf of her child are seen as the "wrong" choices, this could reflect poorly on her as a mother, as well as the child's nascent identity. Choosing an "appropriate" product involves being informed about many aspects including age and size guidelines, safety, and recall information. It can also involve the appropriate gendering of one's child. There are social consequences one may pay for not "doing gender" or performing one's gender role in the way expected by society (West and Zimmerman, 1987). Children can act as symbolic representations of their parents' attitudes and orientations (Bourdieu, 1999), which is one reason why parents may be highly invested in what they choose to purchase for their children. These consumer purchases can convey strong messages to the outside world, as well as acting as forms of socialization for the children themselves (Martens, 2004).

\section{Data and methods}

The data in this study is drawn from in-depth, semi-structured interviews with 25 mothers and expectant mothers. Sixteen of the women were "younger", giving birth in the 2000s. Ten of them were pregnant at the time the interviews took place and six of them had given birth within the previous 18 months. Thirteen of the 16 younger women chose to find out the gender of their unborn baby through ultrasound, while three did not. The remaining nine participants were "older" women who gave birth to their children largely in the 1970s (see Table 1), 
Table I. Characteristics of participants.

\begin{tabular}{|c|c|c|c|c|}
\hline Name $^{a}$ & $\begin{array}{l}\text { Found age } \\
\text { out? }\end{array}$ & & $\begin{array}{l}\text { Marital } \\
\text { status }\end{array}$ & $\begin{array}{l}\text { History of pregnancies and } \\
\text { births at interview }\end{array}$ \\
\hline \multicolumn{5}{|c|}{ Younger mothers: } \\
\hline Nina & Yes & 31 & Married & 2005 (boy), 2007 (girl) \\
\hline Becky & Yes & 34 & Married & $\begin{array}{l}2005 \text { (boy), } 2008 \text { (girl) } \\
\text { [miscarried 2004] }\end{array}$ \\
\hline Stephanie & Yes & 29 & Married & 2008 (girl) \\
\hline Gloria & Yes & 33 & Married & 2007 (boy) \\
\hline Melissa & Yes & 27 & Married & Pregnant ( 27 weeks, boy) \\
\hline Susan & Yes & 32 & Married & Pregnant (28 weeks, twin boys) \\
\hline Sarah & Yes & 29 & Married & Pregnant (37 weeks, boy) \\
\hline Kate & Yes & 30 & Married & Pregnant (36 weeks, girl) \\
\hline Sharon & Yes & 29 & Married & Pregnant (34 weeks, girl) \\
\hline Kara & Yes & 30 & Re-married & Pregnant (36 weeks, girl) \\
\hline Christina & Yes & 34 & Single & Pregnant (33 weeks, boy) \\
\hline Jill & Yes & 26 & Married & $\begin{array}{l}\text { Pregnant (28 weeks, girl), } \\
\text { [miscarried } 2006 \text { \& 2007] }\end{array}$ \\
\hline Holly & Yes & 25 & Engaged & Pregnant (27 weeks, girl) \\
\hline Emily & No & 43 & Re-married & $\begin{array}{l}\text { Pregnant ( } 30 \text { weeks, } \\
\text { twins_-unknown genders) }\end{array}$ \\
\hline Katie & No & 30 & Married & 2005 (boy), 2009 (girl) \\
\hline Beth & No & 29 & Married & 2006 (girl), 2009 (boy) \\
\hline \multicolumn{5}{|c|}{ Older mothers: } \\
\hline Julia & No & 61 & Divorced & 1973 (boy), [miscarried 1972] \\
\hline Eleanor & No & 57 & Divorced & $\begin{array}{l}1980 \text { (boy), I } 983 \text { (girl) } \\
\quad[\text { miscarried twice 1979] }\end{array}$ \\
\hline Mildred & No & 65 & Divorced & 1975 (girl), 1978 (boy) \\
\hline Lillian & No & 62 & Divorced & 1976 (girl), 1979 (girl) \\
\hline Denise & No & 64 & Married & I968 (boy), I97I (girl) \\
\hline Hazel & No & 67 & Divorced & 1969 (boy), I97I (boy) \\
\hline Michelle & No & 64 & Married & I 975 (boy), I 979 (boy), I98। (girl) \\
\hline Theresa & No & 58 & Married & l 977 (girl) \\
\hline Carol & No & 62 & Married & $\begin{array}{l}1974 \text { (boy), I } 976 \text { (boy), } \\
\text { I } 982 \text { (girl), I } 983 \text { (boy) }\end{array}$ \\
\hline
\end{tabular}

${ }^{\mathrm{a}} \mathrm{All}$ names are pseudonyms. 
prior to the routine use of ultrasound technology. Pseudonyms are used throughout in place of real names.

The study participants were recruiteed through two methods. Six of the ten currently pregnant participants were recruited by making an announcement explaining the research at the end of childbirth classes offered at a local hospital. The remaining participants were recruited using snowball sampling techniques, in which participants (or other personal contacts) offered the names of potential participants. No more than two referrals were taken from each participant to insure that they were not all from the same social network. Finding women who had chosen not to learn the sex of their fetus proved to be the most difficult. All interviews were held at the the home or workplace of the subjects. The number of interviews was a result of ending the recruitment process when a point of theoretical saturation had been reached.

Although the "older" women who were interviewed are by necessity providing a (decades later) retrospective perspective on their pregnancy, the in-depth personal narratives they can provide about their experiences are still important. Similar levels of social science research were not being conducted on comparable topics when these women were pregnant and it is important to capture their first-person perspectives while these women are available to provide it. There is still much we can find out from them. For example, in a recent monograph on the history of children's clothing, the only source on the timing of prenatal purchases the author gave was a reference to a 1973 issue of Earnshaw's magazine (Paoletti, 2012). Firstperson narratives are needed to strengthen our knowledge on the topic.

The majority of the younger women (12 of 16) were either pregnant with their first child or had recently given birth to their first child (see Table 1). I had originally intended to only include first-time mothers; however, finding an appropriate comparison group of older mothers willing to participate proved difficult, as having just one child was previously less common. According to the National Center for Health Statistics, the percentage of US women who have only one child doubled from roughly $10 \%$ in the 1960 s to about 1 in 5 in the 2000 s. In the end, two of the nine older women interviewed were mothers of only children, while the other women had two or more children. Due to this challenge, I decided to also include younger mothers who had more than one child to be sure that the differences between the groups were not simply the result of the number of children they had. The results suggest the divergences were not due to their number of children; however, the small number of women who participated in the study means that this is an area where more research should be done. It makes sense that there would be differences in some patterns of consumption when one has a first, second, or third child. We know that mothers are more likely to have formal baby showers with first children (Douglas and Isherwood, 1979), which was illustrated in the interviews. How this might have changed over the decades now that women are more likely to purchase gendered clothing and personalized items for each child deserves attention. During the interviews with women who had multiple children, I asked them to begin by telling about their experiences with their first pregnancy and then speak 
about each subsequent pregnancy. The data for this paper is largely drawn from information about the first births of all 25 women.

Other differences in fertility background also emerged during the interviews. Two women from each group reported a miscarriage. Prior research indicates that experiencing a miscarriage or stillborn birth before a pregnancy can alter consumption patterns by increasing women's reluctance to purchase items early in pregnancy (Layne, 2000). As will be discussed, some indications of this pattern were also found among the women interviewed for this study. In addition, two younger women used in vitro fertilization to become pregnant. Both of these women were first-time mothers who had not previously experienced any adverse pregnancy events. It has not been explored how the use of assisted reproductive technology (ART) might affect prenatal consumption patterns, although ARTs themselves have begun to be examined as a form of consumption (Almeling, 2011). The use of in vitro technology is extremely common in the US with over $1 \%$ of all infants born in the United States every year conceived using ART (Center for Disease Control (CDC), 2011).

The women who took part in this study were fairly homogenous in terms of race, class, and education. All the women who participated were white, as were the fathers of their children. The majority of them (12 of 16 younger and 7 of 9 older) were college educated. All the women were heterosexual, and 18 of the women were currently married, five were divorced, one was single, and one was engaged. The women who were currently pregnant or had recently given birth were 25-34 years old - except for one woman who was 43 years old - and the women who had given birth in the late 1960s to early 1980s were ages 57-67 at the time of their participation (see Table 1).

Each of the interviews lasted between 40 and 60 minutes. All of them were audio-taped and later transcribed. The semi-structured interview guide covered many topics including: if they had an ultrasound, when, and what the experience was like; if they wanted to find out their fetus' sex and why, their reaction to finding out its sex; when they felt their fetus became "a person"; their interactions with the fetus while pregnant, when they started buying things for the fetus, and the nature of the purchases.

I loosely relied upon a grounded theory method of data analysis, which involves taking an open-ended approach to one's data and modifying hypotheses as the analysis proceeds (Glaser and Strauss, 1967). As part of the grounded theory techniques, I used an "issue focused" or thematic approach to data analysis. I handcoded the interview transcripts and developed the conceptual categories. I first coded for specific themes, and then worked on integrating the separate themes into a single coherent story (Weiss, 1994). My final coding categories were developed and defined in an ongoing interaction with the data collection process, due to the iterative nature of data collection and analysis.

Because this study uses a non-random sample, it is not generalizable to any larger population. Like most other qualitative studies, generalizability is not the major purpose of this research but instead, it focuses on describing in detail a 
particular process and experience (Krefting, 1999). In particular, the small sample size and the differences that exist between the women in their fertility background (number of children, miscarriages, use of ART) open the door for several potential issues. It is hoped that the process and theories described here can be built upon to explore each of these areas separately in the future, as well as with samples more diverse in race, social class, and nationality.

\section{Changing conception of the fetus}

The two cohorts of women held noticeable differences in their beliefs about their fetus and its relationship to its mother. Although it would be simplistic to assume that all the changes are solely due to the experience of ultrasound and the discovery of the fetus' sex, the changes do appear related.

One clear difference between the younger women having their children in the 2000s and the women who had their children years earlier, was that the younger women were more likely to conceptualize the fetus as a separate being from early in their pregnancy, which supports previous research (Katz Rothman, 1986, 1989, 1994; Mitchell, 2001; Mitchell and Georges, 1997; Taylor, 2008). The younger women in this study viewed the unborn baby as a separate entity from themselves before the fetus reached the point of viability. Explained one expectant mother:

I'm just kind of a storage space for the baby... I'm just an apartment building. (Sarah, age 29, currently pregnant)

In contrast, an older woman said:

I think it's weird when people talk to the baby before it's born. When mothers or mother-in-laws get down and talk to the belly? Because that's you-that's your body. You know, it's not a baby, it's part of you.' (Eleanor, age 57; 1980 \& 1983)

The contrast between these two quotations is clear. Where the younger woman conceptualized the fetus as separate from her early in pregnancy, the older woman felt it was part of her until much later. This latter view is aligned with Barbara Katz Rothman's (1994) understanding of the way women traditionally experienced pregnancy. She writes, "For women, pregnancy is a slow process of separation; part of us goes on to become someone else" (1994: 263). She argues the combination of increased medical technology and patriarchal perspectives has created the newer perception of babies as, "not growing out of their mothers ... but as separate beings implanted within” (1994: 266).

In addition to ultrasound, the use of ART also appeared likely to increase the probability that the expectant mother viewed the fetus as separate from herself. The two women who were currently pregnant with twins had both used in vitro fertilization to become pregnant (one using her own eggs and one using an egg donor). For both of these women, their "first photo" was actually provided to them by 
their fertility center and was of the embryos when they were in a Petri dish before they were reinserted into the mother's womb. In these photos, the embryo/unborn child was actually separate from its mother and able to be viewed and treated as a separate patient, which one of the women was quick to point out when she pulled out the photograph.

In general, younger women were also more likely to think of the fetus as "a person" from earlier on. Janelle Taylor (2000) claims in her research that when women have an ultrasound and see the fetus, this encourages them to construct a more specific social identity than they would be able to without it, although she does not address the role of sex determination in this process. In the interviews, there were indications that learning the sex of the fetus also encouraged the expectant mother to conceptualize it as "a baby" or "a person" with a unique social identity apart from the ultrasound experience. Gender/sex category is often one of the first things that we notice about someone, and we usually interact with individuals in ways that take into account their sex and/or gender (West and Zimmerman, 1987). We are generally uncomfortable interacting with someone when we do not know their gender, which partly explains why new mothers and fathers are so intent on dressing their newborn sons and daughters in certain (i.e. blue or pink) colors (Lorber, 1994). The colors signify what sex the baby is, so that strangers know how to interact "properly" with a newborn baby who may otherwise give off no other sex or gender indicators. In some ways then it should come as no surprise that expectant mothers are better able to imagine their fetus as "a real baby" after they know its sex.

All of the younger women in the study who chose to find out their baby's sex (13 of 16) reported enjoying being able to use gendered pronouns (or, as a few of them said, "the correct pronouns") both when talking to and about their fetus:

It's more fun to think of the baby as a "him" or a "her" than an "it". You can decorate things better too-but I just really like being able to refer to it as something other than "it", which is something non-human to me. (Holly, age 25; pregnant)

In addition to mentioning the importance of sex in consumption patterns, this woman refers to disliking gender-neutral pronouns as they felt non-human. Three other younger women also mentioned being quite bothered when someone would refer to their unborn child as an "it". For them, knowing the sex of their child helped to indicate its personhood-perhaps because it was hard for the women to picture the fetus as a real child without knowing its sex.

These findings about ultrasound contrast with the earlier work by Katz Rothman (1986) on women who were deciding on whether or not to undergo amniocentesis (a form of invasive prenatal genetic testing). She concluded that amniocentesis, which also allows parents to discover the sex of their fetus, encourages women to experience a "tentative pregnancy". The pregnant women in her study were "tentative" in that they did not fully emotionally or physically engage in their pregnancy until later (often close to 20 weeks), as they waited to find out if 
they would be faced with the decision of whether to abort their fetus due to genetic abnormalities, such as those as associated with Down's Syndrome (Katz Rothman, 1986). They generally also held off purchasing maternity clothes or consuming on behalf of the fetus. Although Katz Rothman's work (1986) may still be accurate for those women who undergo amniocentesis, currently less than 5-10\% of women choose to have that test performed (Nicolaides et al., 2005). The last two decades have seen an increase in the types of non-invasive tests available, many of which are now recommended in place of amniocentesis for all except the most "at risk" women (California Prenatal Screening Program, 2009). None of the women in this study chose to undergo amniocentesis.

\section{Consumption patterns during pregnancy}

Although having children has increased consumption in families for decades, there were noticeable differences in the consumption patterns between younger and older mothers. The younger women's purchases began earlier in the pregnancy and were more likely to be highly gendered. They more frequently engaged in the personalization of items, including buying items with the baby's full name on them before birth. These differences appear to be directly connected to finding out the sex of the baby, as well as influenced by the different ways the women thought about the fetus.

\section{Timing}

In previous generations, mothers would frequently wait until the end of their pregnancy to ready their "layette", which included necessities their child would need initially after birth. There was frequently a sense that purchasing everything a child might need for the first several months of its life before its birth was "tempting fate" or "unlucky". In contrast, many young moms in this study reported that they began buying things for their baby as soon as they found out they were pregnant. They also acquired a great deal more after they found out the baby's gender (often through registering for one or more baby showers), and would have felt unprepared if they did not have "everything" before their child was born.

Among the younger women, the majority (12 of 16) made a purchase for their baby during the first trimester of pregnancy. These purchases were generally small and were usually made in the first few weeks after discovering they were pregnant or right after their first (8-10 week) ultrasound. Items that were purchased included shoes, baby blankets, a teddy bear, and several outfits. A few of the older mothers were critical of younger mothers who start buying baby products immediately:

I find now that people start to buy things as soon as they're pregnant. A friend of mine, her daughter got pregnant and as soon as she found out, she's at Baby Gap. And she needs other things - like food, clothing, and a roof over her head. And health 
care! But they're immediately out there shopping now. (Michelle, age 64; 1975, 1979 \& 1981)

All of the younger mothers had made multiple purchases by the end of their second trimester.

For most women, finding out the gender of their baby at their 20-week ultrasound was an impetus to buy more things. A common buying pattern was described by one younger woman:

\section{[When did you start buying things?]}

Right around the time that I found out it was definitely a boy! Before then I had only purchased one or maybe two things, but then I got some boy things and I registered for my shower right after. [When was that held?] I had my shower when I was 32 weeks along. (Melissa, age 27; pregnant)

This pattern of contemporary mothers purchasing items after learning the sex of their fetus has been mentioned in previous research (Paoletti, 2012). In addition, two of the three mothers who chose not to find out the sex of their fetus also purchased items following the 20-week ultrasound; however, the number of purchases was significantly smaller.

The majority of younger mothers began registering for baby items about half way through their pregnancy and had their baby shower approximately two months before their due date. Baby showers are traditionally seen as important rites of passage that occur most often during first pregnancies and are "rituals of consumption" (Douglas and Isherwood, 1979). All of the younger women but one registered (some with their spouses) for baby shower items, which allowed each of them to have some control over the types of items they received even when it was other people consuming on their behalf.

Older women reported patterns that were quite different, with the women holding their baby showers within a few weeks of their due date and usually not registering for baby items, so they had much less control over the items being purchased. The majority of women reported not buying anything significant until after they had their shower, so they could see what they needed. An older woman explained:

I waited until I had a shower a few weeks before he was born and then filled in things afterward. In my mother's time, she would say that it was bad luck to even have a shower before the baby was born. (Carol, age 62; 1974, 1976, 1982, \& 1983)

As other older women also mentioned, just the decision to have a formal baby shower before the baby was born would have been seen as premature by many people just a generation earlier. This sweeping change may also be influenced by 
the popularity in the US today of online baby registries, where expectant mothers can register for certain items and track online what has been purchased for them, which gives them knowledge to guide their own purchases. The older mothers explained that it was not so much the worry about receiving duplicate items that stopped them from buying items before their showers, instead they contended that purchasing lots of baby items early in pregnancy was just not normative or "not done" when they were pregnant.

These changes in when purchases for unborn babies are made certainly reflect a lack of fear in fetal/infant mortality by the younger women and an eagerness to start consuming on their behalf. As fetal mortality rates among white working and middle class women have not significant changed in the past 30 years, this represents a change of belief in superstition rather than simply a response to an objective change in mortality rates. It also demonstrates the women's belief in the accuracy of ultrasounds in determining sex, since a large amount of the purchases of the younger women who knew the sex were highly gendered. From rooms painted pink to hand-embroidered blankets, these highly gendered and personalized items were the other differences between the two cohorts.

\section{Gendered preparations}

Discovering the sex of their fetus (or as they said, their "baby's gender") through ultrasound allowed the younger women to engage in highly gendered consumption and material preparations. The majority of the younger women created bedrooms and environments specifically geared toward either a boy or girl baby. This was in clear contrast to the older women who tended to prepare gender-neutral environments.

The idea that babies today are being born into (or at least taken home to) environments that are actually more gendered than 30 years ago is intriguing. In many way, norms and social practices have become less focused on gender differences (for example, women in the workforce, men doing housework, Title VIII, Equal Pay Act, etc.), even though some scholars point out that a "stalled revolution" took place in certain aspects and gender change may have plateaued (Damaske, 2011; Hochschild, 1989). Regardless, becoming more differentiated on the basis of gender is unusual; yet as expectant mothers now have half their pregnancies (over four months) to plan for a boy or girl rather than simply a "baby", the result appears to be increased gendering of newborn babies.

\section{[Have you bought anything yet?]}

I have a crib, a changing table, a swing, a stroller. I think I have enough clothes for a year. My mom's gone a little crazy with the shopping. Things at first were more gender neutral but recently we've both been buying boy clothes and things for the room. (Christina, age 34; pregnant) 
All of the women who knew the sex of their unborn babies bought some amount of clothes and items (toys, books, decorations for bedroom) during pregnancy, although the level of gendering varied. Some women were quite enthusiastic about being able to buy gendered items and purchased mostly gendered items, while others were not as eager.

Two of the women expressed ambivalence about their own gendered consumption, as they were not sure about the relationship between their purchases of largely gendered items and their beliefs in egalitarian gender roles. One of them tried to explain her views by saying:

I'm not even one of those people who believe in gender stereotyping. That's not how I was raised. My mom was not a girly girl and my parents worked very hard not to... Well, I got mistaken for a boy a lot but I was actually a girly girl. My mom was a tomboy and she was often like "what's wrong with you?" (Kate, age 30; pregnant)

Although she wanted to be able to purchase "girly girl" outfits for her unborn daughter, she did not see this as necessarily equaling a belief in traditional gender stereotypes. There may be a connection between the beliefs that this young woman expressed, that one can be simultaneously strong and feminine, and third-wave feminism. It has been hypothesized that the trend toward more gendered clothing is due to the rise of third-wave feminism, which is more likely to embrace or accept a gender difference perspective, as opposed to second-wave feminism, which emphasizes gender similarity (Paoletti, 2012).

Sometimes a woman's parents or other relatives also had a role in what she bought. Two women were explicit about feeling pressured by relatives into buying gendered apparel and baby gear before they were quite ready.

\section{[Have you bought anything yet?]}

Me or the family? Yeah, we've started buying the furniture and stuff. My family just gave me five bags of girl stuff! I'm like, let's not go there yet! The stuff I've bought is gender neutral. (Kara, age 30; pregnant)

Although, this study focused on maternal consumption, this woman's statement suggests that it would be useful to have additional research that looks further at how extended family members or friends may also intensify the gendering of unborn babies through consuming on their behalf during pregnancy.

In addition to being gender specific, more than half of the younger women who knew the sex of their fetus also purchased items personalized with a formal given name before the baby was born. The ability to personalize items with the baby's name was seen as another benefit that ultrasound gave expectant mothers.

[Why did you want to find out the baby's gender?] 
All the monogrammed gifts! That's really why we mostly did it. Because both sides only have boys, so we thought that would be a good reason to have one [ultrasound]. But now "uh oh!" because if it's wrong. (laughs). . Everything we have says "Ruth Ann, Ruth Ann", and "RAM" on it. We're thinking maybe "Rutherford Anthony" if it's a boy? (laughs). (Sharon, age 29; pregnant)

This woman is unusual in that most women seemed not to have considered the possibility of the sex determination being wrong. Although ultrasound technicians are supposed to be correct $95-100 \%$ of the time, even the possibility of a mistake was not usually acknowledged.

Personalization is surely encouraged by the baby industry, as the personalization of items costs extra money and also discourages passing down items by siblings. From the perspective of the expectant mother, it was one part of how she created a room that was highly personalized and individualized to what she believed the baby would enjoy. These perceptions by the pregnant women were usually highly gendered, as the sex was one of the only pieces of concrete information the women had upon which to base their choices.

None of the older women engaged in gendered consumption on behalf of their unborn babies for the simple reason that they did not know their baby's sex. The women were equally divided on whether they believed they would have liked to know the sex. One older woman who wished she had the opportunity to discover the sex of her baby explained:

The way I am, I really would have liked to be able to plan - to know what it was beforehand. But it turned out well because everything that we had for John was gender-neutral with maybe a little more of an overtone of a boy because everything we had was red, white, and blue, and that is definitely not pink-like for a girl. (Julia, age 61 ; 1973)

The convenience of being able to plan was the reason highlighted by those older women who said they would have found out the sex if they could. In contrast, other older women said that being able to plan was not a good enough reason and they would not have found out even if given the opportunity.

No, because I would want it to be a surprise. I wanted to feel the love that builds up - that I would love it either way. It's not just the surprise, it's kind of like God didn't want you to know that ahead of time. I know that people today want to know so they can prepare. To me it wouldn't have mattered. I would have loved it no matter what. (Carol, age 62; 1974, 1976, 1982, \& 1983)

You want that to be a climactic moment and to get the most out of it that you can. You know, just have that wonderful kind of moment. Finding out kind of dilutes it, I think. (Denise, age 64; 1968 \& 1971) 
As highlighted by the above quotations, the older women who said they would not want to know the sex thought that knowing ahead of time would take away from the joy of discovery at the moment of birth or thought that it was not "natural" for women to find out ahead of time. Whether or not they are accurate in their perception of what choice they would have made is unclear, as the majority of women today do choose to find out their baby's sex (Marleau and Saucier, 2002).

Two of the three younger women in the sample who chose not to find out the sex of their fetus had answers that were quite similar to that of the older women's answers, in that they wanted to be surprised and to appreciate the moment as it occurred. The third woman said:

I just didn't care which gender she was. And I didn't like how once, as soon as you found out what you were having, everything was automatically all pink or blue. I don't want my child to be so gender stereotypical and that just seemed like the best way to do it. (Beth, age 29; 2006 \& 2009)

This woman appeared to see her decision to not find out the sex (which her partner deferred to her on) as a way of taking a stand against the importance of sex/gender and the stereotypical gender roles into which children are often cast. A few of the other women who chose to find out the sex also complained about the overgendering of newborns that sometimes occurred (which they appeared to be complicit in).

Buying items that are largely gender specific is certainly being encouraged by the baby product industry, as it increases the likelihood that a family will purchase all new products if they have a second child who is the opposite sex and it makes handme-downs less likely (Paoletti, 2012). In many ways it is not a surprise that mothers are choosing to buy gendered clothing for their offspring. There has always been a gender distinction made between the clothing of older children, even if the styles and colors have changed and the extent of the gendering has varied (Cook, 2004; Paoletti, 2012). The significance in the change is largely that infancy and early childhood used to be when was one was most likely to have the least amount of gendering in terms of clothing (for histories of clothing, see Cook, 2004; Paoletti, 2012) and this is no longer true. Although it is clear that the pattern has changed, it is less clear what effect this may have on those children who are brought up in an environment where they are gendered from a time before they are born.

\section{Exceptions with cause}

The noticeable departures from the patterns of early gendered consumption among younger women came from those who had personally experienced unsuccessful pregnancies (see Table 1). Although older women also discussed the effects of miscarriages and stillborns on subsequent pregnancy experiences, the differences were starker for younger women due to the shifting patterns. Those younger women who had previously experienced miscarriages were less likely to buy as 
many baby products before birth and more likely to purchase those that could be returned or saved for future pregnancies because they were not gender specific or personalized. This is aligned with what previous research done on women in the 1990s found (Layne, 2000). Generally they were more aware that something could go wrong and more cautious in embracing the patterns of other younger mothers.

\begin{abstract}
Besides bedroom furniture we have not bought a single thing yet. I can't bring myself to do it. Just because of my medical history, I can't bring myself until it's closer to an actual reality. Everything we registered for was gender neutral. (Jill, age 26; pregnant, two previous miscarriages)
\end{abstract}

This young woman, who was in her third trimester but had yet to experience a successful birth, was very aware of how her previous unsuccessful pregnancies shaped the experience of her current pregnancy. Although she and her husband had chosen to find out the sex of the baby, she did not embrace any of the behaviors that the other expectant mothers did. Another woman who had experienced one miscarriage early in her first pregnancy before having two successful pregnancies (one recently) also was somewhat more cautious than the other younger women.

\footnotetext{
Well, I'm a little superstitious. With both of them we bought them clocks with their name on it before they were born, but we didn't do that with a lot of stuff. My miscarriage was really early on, but still after going through that you...y you don't want to be stuck with all this stuff just in case. (Becky, age 34; 2008 \& 2005, miscarried 2004)
}

In the above quotation, the woman frames her decision to not have many of her baby items personalized before birth as due to "superstition", although in many ways her decision could also be framed as "logical". Certainly 30 years previously, it was seen as the correct way to do things.

\title{
Conclusion
}

This study has used in-depth personal narratives with two cohorts of women to examine how the consumption patterns of expectant mothers have changed now that the vast majority utilizes ultrasound to learn the sex of their fetus during pregnancy. Most research examining the experience of ultrasound has not connected it to consumption patterns (for exceptions, see Taylor, 2000, 2008; Taylor et al., 2004) and how fetal sex determination plays a role in consumption patterns has remained understudied. Although expectant mothers in the 1970s and in the 2000s both purchased necessary items in preparation for the birth of their baby, the types of purchases greatly differed. Those women who became mothers more recently did a large amount of shopping earlier in pregnancy, and the items they bought were highly gendered in color and style, and sometimes tailored to the unborn baby's perceived tastes and formal name. 
That newborn babies today are more likely than three decades ago to be spending their first few months wearing gendered clothing and being surrounded by gender-specific furniture and objects goes against how many people think about gender patterns in the US. Although scholars point out the continuing gender inequality that exists in both public and private realms, it is unusual for gender differences to become more prominent. In fact, recent polls have argued that the lives of men and women have become more similar and symmetrical (Galinsky et al., 2011). Why then do we see these patterns occurring and what are the effects of this increase in early gender socialization? More research needs to be done to fully examine these questions.

It is unclear to what extent the pregnant mothers are the source of the increase in gendered consumption and how much of it is being driven by commercial industries that want to capitalize on having mothers of multiple children buy several sets of baby goods, instead of passing them down. Yet, women do not seem to be unhappy with the gendering of items, as most of the women embraced learning their child's sex before its birth and creating a gendered environment. These younger women believed that the fetus was "separate" and "a person" much earlier on in the pregnancy than the older women did and the gendered consumption patterns appeared to help them to construct a social identity and gain social recognition for the unborn baby.

Looking through another lens, these women are also probably trying to demonstrate that they are, or will be, "good mothers" through the consumption choices that they make. Purchasing items for their child is an important type of carework, which mothers do. It is meaningful activity based on values and beliefs, and also can be a considerable source of anxiety (DeVault, 1991; Pugh, 2009; Warde, 1994). Just as all mothers, and especially middle and upper class mothers, are judged by their ability to live up to the ideals of "intensive mothering" (Hays, 1996), these women perceive that their ability to mother effectively may be judged by how they dress their child and the objects they surround him or her with. Although mothers of all social classes care about the purchases they make for their children, lowincome women are not always able to provide the same amount of goods or to provide them at will to their children (Pugh, 2009). Whether income, social class, or societal affluence affects the level to which mothers engage in gendered pre-birth consumption patterns should be further explored.

Although there is ample evidence that the consumption choices that parents make are an influential part of a child's socialization process (Cook, 2004; Martens, 2004; Pugh, 2009) and that gender socialization is of critical importance (DeVault, 1991; Lorber, 1994), it is unclear how this increased socialization during a child's earliest months may influence them. When pregnant women engage in extensive early consumption on behalf of a fetus that is not yet viable, it is worthwhile asking whether they are consuming on behalf of the child, or for their own pleasure. Future research that further explores the effects of fetal sex determination should consider the effects on both mothers and children, as well as the entire web of social relationships in which both are situated. 


\section{Funding}

This research received no specific grant from any funding agency in the public, commercial, or not-for-profit sectors.

\section{References}

Almeling R (2011) Sex Cells: The Medical Market for Eggs and Sperm. Berkeley, CA: University of California Press.

Bailey M and Ulman B (2005) Trillion-Dollar Moms: Marketing to a New Generation of Mothers. Chicago, IL: Dearborn Trade Publishing.

Bourdieu P (1984) Distinction: A Social Critique of the Judgment of Taste. London: Routledge \& Kegan Paul.

Bourdieu P (1999) The Weight of the World: Social Suffering in Contemporary Society. Cambridge: Polity Press.

California Prenatal Screening Program (2009) Provider handbook: Genetic disease screening program. Available at: http:/www.cdph.ca.gov/programs/pns/Documents/ Provider\%20Handbook\%20\%202009\%20WEB.pdf (accessed 10 May 2013).

Casper LM and Bianchi SM (2001) Trends in the American Family. Thousand Oaks, CA: Sage Publications.

Center for Disease Control (2011) Preliminary ART fertility clinic success rates report. Available at: http://www.cdc.gov/ART/ (accessed 9 May 2013).

Cook DT (2004) The Commodification of Childhood. Durham, NC: Duke University Press.

Cook DT (2008) The missing child in consumption theory. Journal of Consumer Culture 8(2): 219-243.

Damaske S (2011) For the Family? How Class and Gender Shape Women's Work. New York: Oxford University Press.

DeVault M (1991) Feeding the Family: The Social Organization of Caring as Gendered Work. Chicago, IL: University of Chicago Press.

Douglas M and Isherwood B (1979) The World of Goods. New York: Basic Books.

Featherstone M (1991) Consumer Culture and Postmodernism. London: Sage.

Galinsky, E, Aumann K and Bond JT (2011) Times Are Changing: Gender and generation at work and at home. Report of the 2008 National Study of the Changing Workforce, Families and Work Institute. New York City, New York. Originally issued 2009, revised August 2011.

Giddens A (1991) Modernity and Self-identity: Self and Society in the Late Modern Age. Cambridge: Polity Press.

Glaser B and Strauss A (1967) The Discovery of Grounded Theory. Chicago, IL: Aldine.

Gregg R (1995) Pregnancy in a High-tech Age: Paradoxes of Choice. New York: New York University Press.

Haraway D (1997) Modest_Witness@Second_Millennium. New York: Routledge.

Hays S (1996) The Cultural Contradictions of Motherhood. New Haven, CT: Yale University Press.

Hochschild A (1989) The Second Shift. New York: Avon.

Hochschild A (2003) The Commercialization of Intimate Life. Berkeley, CA: University of California Press.

Katz Rothman B (1986) Tentative Pregnancy: How Amniocentesis Changes the Experience of Motherhood. New York: Norton. 
Katz Rothman B (1989) Recreating Motherhood: Ideology and Technology in a Patriarchal Society. New York: Norton.

Katz Rothman B (1994) The tentative pregnancy: Then and now. In: Rothenberg KH and Thomas EJ (eds) Women and Prenatal Testing: Facing the Challenges of Genetic Testing. Columbus, OH: Ohio State University Press, pp. 260-270.

Krefting L (1999) Rigor in Qualitative Research: The Assessment of Trustworthiness. In: Milinki A (ed.) Cases in Qualitative Research: Research Reports for Discussion and Evaluation. Los Angeles, CA: Pyrczak Publishing.

Layne L (2000) "He was a real baby with baby things": A material culture analysis of personhood, parenthood and pregnancy loss. Journal of Material Culture 5(3): 321-345.

Lorber J (1994) The Paradoxes of Gender. New Haven, CT: Yale University Press.

Marleau J and Saucier JF (2002) Preference for a first-born boy in western society. Journal of Biosocial Science 34(1): 13-27.

Martens L (2004) Bringing children and parents into the sociology of consumption. Journal of Consumer Culture 4(2): 155-182.

Miller D (1998) A Theory of Shopping. Ithaca, NY: Cornell University Press.

Mitchell L (2001) Baby's first picture: Ultrasound and the politics of fetal subjects. Toronto: University of Toronto Press.

Mitchell L and Georges E (1997) Cross-cultural cyborgs: Greek and Canadian women's discourses on fetal ultrasound. Feminist Studies 23(2): 373-401.

Nicolaides KH, Chervenak FA, McCullough LB, et al. (2005) Evidence-based obstetric ethics and informed decision-making by pregnant women about invasive diagnosis after first-trimester assessment of risk for trisomy 21. American Journal Obstetrics \& Gynecology 193(2): 322-326.

Oakley A (1980) Women Confined: Toward a Sociology of Childbirth. Oxford: Martin Roberston.

Oakley A (1984) The Captured Womb: A History of the Medical Care of Pregnant Women. Oxford: Basil Blackwell Publishers.

Paoletti J (2012) Pink and Blue: Telling the Boys from the Girls in America. Bloomington, IN: Indiana University Press.

Petchesky R (1987) Fetal images: The power of visual culture in the politics of reproduction. Feminist Studies 13(2): 263-292.

Pugh A (2009) Longing and Belonging: Parents, Children, and Consumer Culture. Berkeley, CA: University of California Press.

Sandelowski M (1994) Separate, but less equal: Fetal ultrasonography and the transformation of expectant mother/fatherhood. Gender and Society 8(2): 230-245.

Taylor J (2000) Of sonograms and baby prams: Prenatal diagnosis, pregnancy and consumption. Feminist Studies 26(2): 391-418.

Taylor J (2008) The Public Life of the Fetal Sonogram: Technology, Consumption and the Politics of Reproduction. New Brunswick, NJ: Rutgers University Press.

Taylor J, Layne L and Wozniak D (eds) (2004) Consuming Motherhood. New Brunswick, NJ: Rutgers University Press.

Warde A (1994) Consumption, identity-formation, and uncertainty. Sociology 28(4): 877-898.

Weiss R (1994) Learning from Strangers: The Art and Method of Qualitative Interview Studies. New York: The Free Press.

West C and Zimmerman D (1987) Doing gender. Gender \& Society 1(2): 125-151. 


\section{Author's Biography}

Medora W Barnes is an assistant professor of sociology at John Carroll University. Her research interests focus on family lifecourse transitions, parenthood, gender and work-family integration. 